\title{
KEPATUHAN WAJIB PAJAK KOPERASI
}

\author{
RADEN ALEM JANITRA \\ Universitas Islam Indonesia, Kampus Condongcatur Ring Road Utara, Condongcatur, Depok, Sleman, \\ Yogyakarta 55283, Indonesia \\ janitraalem@gmail.com
}

\begin{abstract}
Tax has a big role as a source of state revenue. Tax has a big role as a source of state revenue. Because taxes have an important role,then the tax sector revenue to be something that is reliable, when the natural resource sector revenue unreliable. Indonesia is one country that has problems related to the lack of awareness of taxpayers to pay taxes. The impact of a lack of public awareness in fulfilling obligations is not achieving the percentage of tax revenue in accordance with previously determined. This study aims to examine the effect of the application of the modernization of the tax administration system, knowledge of taxation and tax sanctions on taxpayer compliance.
\end{abstract}

Keywords: Tax compliance, modernization of the tax administration system, knowledge of taxation, tax sanctions

Abstrak: Pajak memiliki peran besar sebagai sumber penerimaan negara. Pajak memiliki peran besar sebagai sumber penerimaan negara. Karena pajak memiliki peran penting, maka penerimaan sektor pajak menjadi sesuatu yang dapat diandalkan, ketika pendapatan sektor sumber daya alam tidak dapat diandalkan. Indonesia adalah salah satu negara yang memiliki masalah terkait dengan kurangnya kesadaran wajib pajak untuk membayar pajak. Dampak dari kurangnya kesadaran masyarakat dalam memenuhi kewajiban adalah tidak mencapai persentase penerimaan pajak sesuai dengan yang ditentukan sebelumnya. Penelitian ini bertujuan untuk menguji pengaruh penerapan modernisasi sistem administrasi perpajakan, pengetahuan perpajakan dan sanksi pajak terhadap kepatuhan wajib pajak.

Kata kunci: Kepatuhan wajib pajak, modernisasi sistem administrasi, pengetahuan perpajakan, pajak sanksi

\section{PENDAHULUAN}

Pembayaran pajak merupakan wujud serta peran masyarakat dalam mensukseskan pembangunan nasional. Pembayaran ini bertujuan untuk meningkatkan kesejahteraan kehidupan masyarakat melalui penambahan dan peningkatan kualitas layanan publik. Dalam rangka meningkatkan penerimaan negara melalui sektor pajak, pemerintah telah melakukan segala cara untuk mengoptimalkan penerimaan sektor pajak. Salah satunya adalah dengan melalui peningkatan kepatuhan wajib pajak orang pribadi maupun wajib pajak badan.

Hal yang terpenting dalam pemungutan pajak adalah kesadaran masyarakat membayar pajak. Masyarakat sering merasa bahwa ketika mereka membayar pajak mereka tidak merasakan efek dari hasil pembayaran pajak. Padahal manfaat yang dirasakan adalah tersedianya fasilitas publik. Karena ketidaktahuan inilah yang menyebabkan banyak sekali wajib pajak yang tidak patuh dalam membayar pajak. Ketidakpatuhan membayar 
pajak menjadi permasalahan utama yang dihadapi Direktorat Jenderal Pajak.

Permasalahan ketidakpatuhan wajib pajak masih menjadi masalah yang terus dihadapi pemerintah Indonesia. Dalam hal kepatuhan pajak negara Indonesia jauh lebih rendah dibanding dengan negara-negara tetangga. Sebagai contoh, ketidakpatuhan pembayar pajak di Malaysia adalah 13 persen dan di Vietnam adalah 16 persen. Rendahnya kepatuhan pajak masyarakat Indonesia akan berdampak pada kekuatan perekonomian nasional (Julianto, 2017). Penerimaan dari sektor pajak inilah yang akan berperan dalam meningkatkan kesejahteraan masyarakat Indonesia, tak terkecuali bagi masyarakat di provinsi Daerah Istimewa Yogyakarta.

Penelitian terdahulu yang berkaitan dengan kepatuhan wajib pajak telah banyak dilakukan, seperti yang dilakukan Aryati (2012). Penelitian yang dilakukan Aryati (2012) menggunakan variabel lingkungan wajib pajak sebagai variabel independen. Penelitian lain dari tahun 2012 adalah dari Tahar dan Sandy (2012).

. Penelitian ini hanya menggunakan variabel sanksi pajak dan pengetahuan pajak secara keseluruhan dan mengambil populasi wajib pajak koperasi sedangkan penelitian Tahar dan Sandy (2012) mengambil variabel independen persepsi wajib pajak atas pelayanan KPP, sanksi perpajakan dan pengetahuan atas penghasilan kena pajak dan menggunakan sampel wajib pajak orang pribadi. Penelitian terdahulu juga telah dilakukan Fasmi dan Misra (2014). Perbedaan penelitian ini dengan penelitian Fasmi dan Misra (2014) adalah populasi yang digunakan dalam penelitian ini adalah wajib pajak koperasi sedangkan populasi penelitian Fasmi dan Misra (2014) adalah pengusaha kena pajak.

Tujuan penelitian adalah menguji pengaruh penerapan modernisasi sistem administrasi perpajakan, pengetahuan perpajakan dan sanksi perpajakan terhadap kepatuhan Wajib Pajak di KPP Pratama Yogyakarta.
Dalam Theory of Planned Behavior (TPB) dijelaskan bahwa perilaku yang ditimbulkan oleh individu muncul karena adanya niat untuk berperilaku (Ajzen, 2005).Munculnya niat untuk berperilaku disebabkan oleh tiga hal (Ajzen, 2005) yaitu Behavioral beliefs merupakan keyakinan individu akan hasil dari suatu perilaku dan evaluasi atas hasil tersebut (beliefs strength and outcome evaluation), Normative beliefs yaitu keyakinan tentang harapan normatif orang lain dan motivasi untuk memenuhi harapan tersebut (normative belief and motivation comply) dan Control beliefs merupakan keyakinan mengenai keberadaan hal-hal yang mendukung atau menghambat kinerja dari perilaku dan persepsinya tentang seberapa kuat hal-hal yang mendukung dan menghambat perilakunya tersebut (perceived behavioral control).

Teori atribusi menjelaskan bagaimana perilaku seseorang yang disebabkan oleh faktor internal seperti karakter, sikap dan lain-lain ataupun faktor eksternal seperti situasi atau keadaan tertentu yang dapat mempengaruhi perilaku individu. Pada dasarnya, teori atribusi menjelaskan bahwa bila perilaku seseorang diamati oleh individu-individu, mereka mencoba untuk menentukan apakah itu ditimbulkan secara internal atau eksternal (Robbins 2008).

Menurut Robbins (2008) penyebab perilaku dalam persepsi sosial dibagi menjadi dua hal yaitu penyebab internal (dispositional attribution) dan penyebab eksternal (situational attribution). Penyebab internal (dispositional attribution) adalah penyebab yang berasal dari dalam diri seseorang seperti karakter pribadi, motivasi dan persepsi seseorang. Penyebab eksternal (situational attribution) adalah penyebab yang berasal dari lingkungan yang mendapat mempengaruhi perilaku seseorang seperti keadaan sosial, pandangan masyarakat, nilai-nilai sosial.

Modernisasi sistem administrasi merupakan pelaksanaan dari berbagai program dan kegiatan yang ditetapkan dalam reformasi administrasi perpajakan jangka menengah. 
Dapat disimpulkan bahwa penerapan sistem administrasi perpajakan modern mengalami penyempurnaan atau perbaikan kinerjanya, baik secara individu, kelompok, maupun kelembagaan (Madewing 2013).

$$
\text { Pengetahuan pajak adalah }
$$

pengetahuan dimana wajib pajak mengetahui tentang wawasan mengenai konsep pajak sesuai dengan Undang-Undang perpajakan yang dapat meningkatkan kepatuhan wajib pajak (Sudrajat \& Ompusunggu 2015). Pengetahuan merupakan hasil pemahan seseorang yang terjadi melalui proses penginderaan terhadap suatu objek yang berkaitan dengan perpajakan (Burhan 2015).

Sanksi pajak adalah sanksi yang bertujuan untuk mengurangi pelanggaran perpajakan. Selain itu, sanksi perpajakan merupakan jaminan bahwa ketentuan peraturan perundang-undangan (norma perpajakan) akan dipatuhi, atau dengan kata lain sanksi perpajakan adalah alat pencegah (preventif) yang bertujuan agar wajib pajak tidak melanggar norma perpajakan (Mardiasmo 2016).

Kepatuhan wajib pajak adalah suatu keadaan Wajib Pajak memenuhi semua kewajiban perpajakan dan melaksanakan hak perpajakannya (Sifanuri, 2017). Penelitian yang dilakukan oleh Sapriadi (2013) menjelaskan bahwa kepatuhan pajak terbagi menjadi dua kategori, yaitu kepatuhan pajak formal dan kepatuhan pajak material. Hipotesis yang akan diuji adalah:

$\mathrm{H1}$ : Modernisasi sistem administrasi berpengaruh positif terhadap kepatuhan Wajib Pajak koperasi.

H2: Pengetahuan perpajakan berpengaruh positif terhadap kepatuhan Wajib Pajak koperasi.

H3: Sanksi perpajakan berpengaruh positif terhadap kepatuhan Wajib Pajak koperasi.

\section{METODA}

Populasi dalam penelitian ini adalah seluruh wajib pajak koperasi yang terdaftar di KPP Pratama Yogyakarta pada tahun 2017 sebanyak 193 wajib pajak.Teknik penentuan sampel dalan penelitian menggunakan metode sampling insidental. Penelitian ini menggunakan data primer yang dikumpulkan untuk mencapai tujuan penelitian. Data primer dalam penelitian ini diperoleh dengan membagikan kuesioner kepada responden yaitu wajib pajak koperasi yang terdaftar di KPP Pratama Yogyakarta. Pengukuran variabel berdasarkan penelitian terdahulu yang dapat dilihat pada tabel berikut:

Tabel 1 Item Pernyataan Kepatuhan Wajib Pajak

\begin{tabular}{lll}
\hline \multicolumn{1}{c}{ Variabel } & \multicolumn{1}{c}{ Pernyataan } & \multicolumn{1}{c}{ Referensi } \\
\hline Kepatuhan & Mendaftarkan diri sebagai wajib pajak secara sukarela ke & Sifanuri \\
Wajib Pajak & KPP (Kantor Pelayanan Pajak) adalah kewajiban saya & (2017) \\
& sebagai Wajib Pajak & \\
& Pengisian SPT (Surat Pemberitahuan) sesuai dengan \\
& ketentuan perundang-undangan dan melaporkannya \\
& dengan tepat waktu adalah hal yang penting \\
& Penyampaian SPT ke tepat waktu sebelum batas akhir \\
& penyampaian SPT adalah hal yang penting & \\
& Tunggakan pajak terutang merupakan hal yang merugikan \\
& negara \\
& Penghitungan pajak yang terutang dengan benar adalah \\
& hal yang penting untuk dilakukan \\
\hline
\end{tabular}




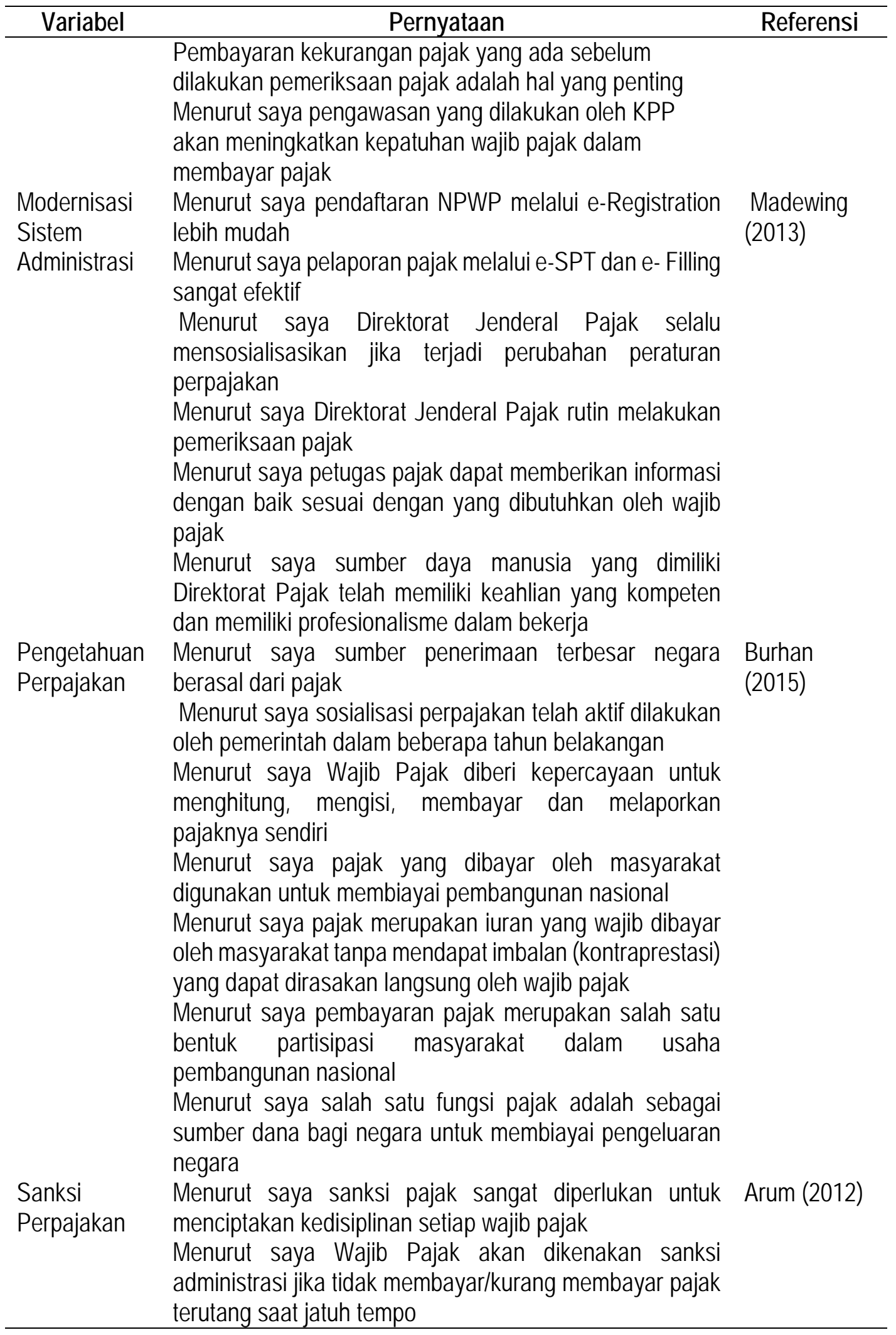




\begin{tabular}{lll}
\hline Variabel & \multicolumn{1}{c}{ Pernyataan } & Referensi \\
\hline & Menurut saya sanksi yang diberikan kepada wajib pajak & \\
& harus sesuai dengan besar kecilnya pelanggaran yang & \\
& sudah dilakukan & \\
& Menurut saya sanksi pajak akan diterapkan jika \\
bertentangan dengan peraturan yang berlaku
\end{tabular}

\section{HASIL DAN PEMBAHASAN}

Gambaran umum responden sebagai berikut:

Tabel 2 Jumlah Responden Menurut Jenis Badan Usaha Koperasi

\begin{tabular}{ccc}
\hline Jenis Badan Usaha Koperasi & Jumlah & Persentase \\
\hline Koperasi Serba Usaha & 36 & $51,4 \%$ \\
Koperasi Simpan Pinjam & 14 & $20,0 \%$ \\
Koperasi Pegawai Republik Indonesia & 4 & $5,7 \%$ \\
Koperasi Karyawan & 11 & $15,7 \%$ \\
Koperasi Syariah/BMT & 5 & $7,1 \%$ \\
Total & 70 & $100,0 \%$ \\
\hline
\end{tabular}

Dari tabel di atas dapat diketahui bahwa responden dari Koperasi Serba Usaha berjumlah 36 orang atau sebesar 51,4\%, responden dari Koperasi Simpan Pinjam berjumlah 14 orang atau sebesar 20,0\%, responden dari Koperasi Pegawai Republik Indonesia berjumlah 4 orang atau sebesar 5,7\% responden dari Koperasi Karyawan berjumlah 11 orang atau sebesar $15,7 \%$, dan responden dari Koperasi Syariah/BMT berjumlah 5 orang atau sebesar $7,1 \%$. Dengan demikian dapat disimpulkan mayoritas responden wajib pajak koperasi yang terdaftar di KPP Pratama Yogyakarta berasal dari Koperasi Serba Usaha.

Pengujian ini dilakukan untuk mengetahui signifikansi pengaruh dari ketiga independen terhadap variabel dependen secara parsial. Koefisien modernisasi sistem administrasi perpajakan (X1) sebesar 0,169 dengan nilai probabilitas (Sig.) sebesar 0,000. Oleh karena nilai probabilitas (Sig.) sebesar $0,000<0,05$ maka Ha diterima. Artinya, modernisasi sistem administrasi perpajakan berpengaruh signifikan terhadap kepatuhan wajib pajak koperasi.
Koefisien variabel pengetahuan perpajakan (X2) sebesar 0,112 dengan nilai probabilitas (Sig.) sebesar 0,000. Oleh karena nilai probabilitas (Sig.) sebesar 0,000 0,05 maka Ha diterima. Artinya, pengetahuan perpajakan berpengaruh signifikan terhadap kepatuhan wajib pajak koperasi. Koefisien sanksi perpajakan (X3) sebesar 0,138 dengan nilai probabilitas (Sig.) sebesar 0,000 . Oleh karena nilai probabilitas (Sig.) sebesar 0,000 < 0,05 maka Ha diterima. Artinya, sanksi perpajakan berpengaruh signifikan terhadap kepatuhan wajib pajak koperasi.

\section{PENUTUP}

Berdasarkan hasil analisis data dan pembahasan mengenai faktor-faktor yang mempengaruhi kepatuhan wajib pajak koperasi pada KPP Pratama Yogyakarta dapat diambil kesimpulan adalah penerapan modernisasi sistem administrasi perpajakan, pengetahuan perpajakan dan sanksi perpajakan berpengaruh signifikan positif terhadap kepatuhan wajib pajak 
koperasi yang terdaftar di KPP Pratama Yogyakarta. Terkait dengan kesimpulan yang telah diperoleh, penulis mengajukan beberapa rekomendasi yang diharapkan dapat menjadi bahan masukan bagi pihak-pihak yang berkepentingan. Adapun rekomendasi yang diajukan antara lain: Faktor lingkungan wajib pajak memoderasi hubungan antara modernisasi sistem administrasi, pengetahuan perpajakan dan sanksi perpajakan terhadap kepatuhan wajib pajak koperasi, Oleh karena itu, disarankan kepada pihak Direktorat Jenderal
Pajak (DJP) untuk menambah intensitas sosialisasi dengan pemasangan iklan melalui media masa ataupun dengan pemberian brosur yang informasinya mempertimbangkan faktor lingkungan wajib pajak. Bagi KPP Pratama Yogyakarta agar terus meningkatkan sosialisasi atau penyuluhan terhadap wajib pajak khususnya badan usaha koperasi di Kota Yogyakarta. Selain itu perlu adanya kegiatan mengunjungi langsung tempat yang sekiranya berpotensi banyak wajib pajak UMKM .

\section{REFERENSI:}

Ajzen Icek. 2005. Attitudes, Personality and Behavior (2 edition). New York: Open University Press; 2 edition (November 1, 2005).

Aryati, T. 2012. Analisis Faktor - Faktor Yang Mempengaruhi Tingkat Kepatuhan Wajib Pajak Badan. Jurnal Media Ekonomi Dan Manajemen Universitas Trisakti, 25(1), 13-29.

Burhan, H. P. 2015. Pengaruh sosialisasi perpajakan, pengetahuan perpajakan, persepsi wajib pajak tentang sanksi pajak dan implementasi PP Nomor 46 tahun 2013 terhadap kepatuhan wajib pajak orang pribadi ( studi empiris pada wajib pajak di Kabupaten Banjarnegara ). Diponegorojournalof Accounting, 4(2), 1-15.

Fasmi, L., \& Misra, F. 2014. Modernisasi sistem administrasi perpajakan dan tingkat kepatuhan pengusaha kena pajak. Jurnal Akuntansi Multiparadigma Universitas Brawjaya, 5(1), 1-169.

Julianto, P. A. 2017, July 19). Ditjen Pajak : Kepatuhan Bayar Pajak Masyarakat Indonesia Masih Rendah. Diambil 7 Maret 2018, dari

https://ekonomi.kompas.com/read/2017/07/19/193000326/ditjen-pajak--kepatuhan-bayar-pajakmasyarakat-indonesia-masih-rendah

Mardiasmo. 2016. Perpajakan Edisi Terbaru (1st editio). Yogyakarta: Andi Publisher.

Robbins, S. 2008. Perilaku Organisasi. (Diana Angelica, Ed.) (1st ed.). Jakarta: Salemba Empat.

Sapriadi, D. 2013. Pengaruh Kualitas Pelayanan Pajak, Sanksi Pajak dan Kesadaran Wajib Pajak Terhadap Kepatuhan Wajib Pajak Dalam Membayar PBB (Pada Kecamatan Selupu Rejang). Skripsi Universitas Negeri Padang, 1-34.

Sifanuri, H. 2017. Pengaruh Modernisasi Sistem Adminitrasi Perpajakan, Sosialisasi Perpajakan, Kesadaran Perpajakan, Sanksi Perpajakan Terhadap Kepatuhan Wajib Pajak (Studi Kasus Wajib Pajak Orang Pribadi Memiliki Usaha Yang Terdaftar Pada Kantor Pelayanan Pajak Pratama Pur. Skripsi Universitas Muhammadyah Purwekerto, 1(1), 1-16.

Sudrajat, A., \& Ompusunggu, A. P. 2015. Pemanfaatan teknologi Informasi , Sosialisasi Pajak, Pengetahuan Perpajakan , dan Kepatuhan Pajak. Jurnal Riset Akuntansi Dan Perpajakan JRAP Universitas Pancasila, 2(2), 193-202.

Tahar, A., \& Sandy, W. 2012. Pengaruh Persepsi Wajib Pajak Atas Pelayanan KPP, Sanksi Perpajakan dan Pengetahuan Atas Penghasilan Kena Pajak Terhadap Kepatuhan Wajib Pajak. Jurnal Akuntansi Dan Investasi Universitas Muhammadiyah Yogyakarta, 12(185-196), 185-196. 